\title{
Effect of Reed Vegetation on Evapotranspiration and Treatment Performance with Vertical Subsurface Flow Constructed Wetlands in the Treatment of Landfill Leachate
}

\author{
Tokuo Yano ${ }^{1, *}$, Masatomo Nakayama ${ }^{2}$, Kazuhiro $\operatorname{Yamada}^{1}$, Akiko Inoue-Kohama ${ }^{1}$, Shinya Sato ${ }^{3}$, \\ Keijiro Enari ${ }^{1}$ \\ ${ }^{1}$ Department of Environment and Applied Chemistry, Tohoku Institute of Technology 35-1 Yagiyama-kasumicho Taihaku-ku, Sendai, \\ 982-8577, Japan \\ ${ }^{2}$ Department of Civil Engineering and Management, Tohoku Institute of Technology 35-1 Yagiyama-kasumicho Taihaku-ku, Sendai, \\ 982-8577, Japan \\ ${ }^{3}$ Sendai Kankyo Kaihatsu Co., Ltd, 460-1 Aonogi-Imozawa Aoba-ku, Sendai 989-3212, Japan
}

Received December 10, 2020; Revised January 22, 2021; Accepted February 24, 2021

\section{Cite This Paper in the following Citation Styles}

(a): [1] Tokuo Yano, Masatomo Nakayama, Kazuhiro Yamada, Akiko Inoue-Kohama, Shinya Sato, Keijiro Enari, "Effect of Reed Vegetation on Evapotranspiration and Treatment Performance with Vertical Subsurface Flow Constructed Wetlands in the Treatment of Landfill Leachate," Environment and Ecology Research, Vol. 9, No. 1, pp. 30 - 38, 2021. DOI: 10.13189/eer.2021.090102.

(b): Tokuo Yano, Masatomo Nakayama, Kazuhiro Yamada, Akiko Inoue-Kohama, Shinya Sato, Keijiro Enari (2021). Effect of Reed Vegetation on Evapotranspiration and Treatment Performance with Vertical Subsurface Flow Constructed Wetlands in the Treatment of Landfill Leachate. Environment and Ecology Research, 9(1), 30 - 38. DOI: 10.13189/eer.2021.090102.

Copyright $(2021$ by authors, all rights reserved. Authors agree that this article remains permanently open access under the terms of the Creative Commons Attribution License 4.0 International License

\begin{abstract}
In this study, the effect of reed vegetation on evapotranspiration (ET) and treatment performance was estimated, and a commonly used meteorological estimate of potential evapotranspiration (PET) was compared with ET with vertical subsurface flow constructed wetlands (VSSFs) in the treatment of the high salinity of landfill leachates. The experimental approaches consisted of three runs: Run A was a poor reed vegetation bed, Run B was a dense reed vegetation bed, and Run $\mathrm{C}$ was a bed without reeds. The results of this study are as follows: The salinities of the leachate inflow in Run A and Run B were $15.8 \pm 1.9 \mathrm{~g}$ $\mathrm{Cl}^{-} / \mathrm{L}$ and $15.5 \pm 2.8 \mathrm{~g} \mathrm{Cl}^{-} / \mathrm{L}$, respectively. The average ETs of Run A, Run B and Run C were $4.2 \mathrm{~mm} / \mathrm{d}, 7.4 \mathrm{~mm} / \mathrm{d}$ and $3 \mathrm{~mm} / \mathrm{d}$, respectively. The annual ET rates of Run A, Run B and Run C were $1535 \mathrm{~mm}, 2702 \mathrm{~mm}$ and $1101 \mathrm{~mm}$, respectively. On the other hand, those of PET estimated on the basis of the Hamon equation of 2017and 2018 were $741 \mathrm{~mm}$ and $791 \mathrm{~mm}$, respectively. The PET rate was much less compared to the ET rate in the dense vegetation bed. It was necessary to consider site-specific factors such as
\end{abstract}

growth of plants in the evaluation of the water budget. The water loss by evapotranspiration in Run B was much more than those in Run A and Run C. Although the removal rates calculated from the concentration between inflow and outflow did not differ between the dense vegetation bed and the poor vegetation bed, the load reduction rates calculated from the water budget differed between dense vegetation and poor vegetation.

Keywords Reed Vegetation, VSSF, Evapotranspiration, Water Budget, Treatment Performance

\section{Introduction}

Constructed wetlands (CWs) are widely known to save energy, to be low cost, to have environmental friendliness and to provide sustainability for the wastewater treatment system. They have been used for treating various types of 
wastewater around the world including domestic, agricultural, industrial wastewaters and various runoff waters $[1,2]$.

CWs also have been frequently used for the treatment of landfill leachates in many countries [3]. In spite of different views on leachate treatment, many experts agreed that an on-site treatment facility was needed, since it was easy to operate, and ecological in terms of costs and energy [4].

Various kinds of plants are planted in CWs: cattail (Typha latifolia L.), reed (Phagmites australis Trin ex Steudel), rush (Juncus effusus L.), yellow flag (Iris pseudacorus L.), managrass (Glyceria maxima), giant reed (Arundo donax L.), and willow (Salix sp.) $[5,6]$.

There are several roles for each of the wetland plants on the CWs [7-9], which are: (1) Prevention of clogging by the rhizomes of plants (2) Oxygen release from the rhizome (3) The offer of a habitat of a rhizosphere (4) Uptake of nutrients, and (5) The offer of a natural landscape. Vymazal and Kropfelva published a thorough literature review on the role of plants in CWs [10]. However, the mechanisms by which macrophytes perform water treatment in CWs are under debate. Evapotranspiration (ET) is one of the most important roles of plant [11]. CWs receive water through inflow and precipitation, and lose water to outflow, evaporation and transpiration, i.e., evapotranspiration. Plants have a critical role in determining the dynamics of water loss, mainly through ET. The ET of emergent macrophytes is a significant process in CWs. Difficulties in accurately calculating ET in CWs can lead to inaccurate water balance [12].

Simple meteorological methods or off-site ET data are often used to estimate ET, but these approaches do not include potentially important site specific factors such as plant communities, root zone, water level, and soil property. Chazarenc showed the importance of evapotranspiration during hot periods in natural wetlands and also in CWs [13]. It is of particular importance that leachate volume decreases as a result of ET in CWs [14]. ET therefore might be used in CWs for landfill leachate treatment. Such CWs are planted with macrophytes like willows, poplars and reeds, as the plants that are recommended for landfill leachate ET [15]. Many researchers reported $\mathrm{CWs}$ for landfill leachate treatment with willows [16-21]. Landfill leachates contain various quantities of undesirable, and even toxic, organic and inorganic substances [3]. Bialowiec et. al. have showed that the common reed is the most suitable plant for landfill leachates, because of their very high ET rates, high biomass yield and high resistance to pollutant load [15]. Its degree of success has varied but not exceeded a $50 \%$ removal efficiency of such pollutants as COD, BOD, and nitrogen [22]. Most of landfill leachate in Japan contain a high salinity which is close to that of sea water [23-25]. Many kinds of plants are difficult to grow under high salinity conditions. It is commonly assumed, however, that reeds can tolerate salinity to a high degree. Matoh demonstrated that reeds were successfully grown at chloride concentrations of up to $17.8 \mathrm{gCl}^{-} / \mathrm{L}$ [26], and reeds could grow normally until $10.7 \mathrm{gCl}^{-} / \mathrm{L}$. Barr reported that $P$. australis could tolerate salinity to quite a high degree of up to $7.3 \mathrm{gCl}^{-} / \mathrm{L}$ for normal growth, surviving at up to $12.7 \mathrm{gCl}^{-} / \mathrm{L}$ [27]. Mauchamp demonstrated that reed growth decreased as salinity increased $(50 \%$ decrease at $4.6 \mathrm{~g} \cdot \mathrm{Cl}^{-} / \mathrm{L}$ when compared to freshwater) and a $7-100 \%$ mortality depending on population, occurred at $9.1 \mathrm{gCl}^{-} / \mathrm{L}$ and $12.1 \mathrm{gCl}^{-} / \mathrm{L}[28]$. Although, there were few studies concerning the treatment of high salinity landfill leachate with constructed wetlands, several reports concerning horizontal subsurface constructed wetlands (HSFs) were given during past several years [23-25]. The ET capacity of reeds in VSSFs in different type of reed vegetation and the effect of reed vegetation on the treatment performance in the treatment of high salinity landfill leachate have not been thoroughly investigated.

The objectives of this study were to estimate the effect of reed vegetation on ET and the treatment performance, and to compare a commonly used meteorological estimate of potential evapotranspiration (PET) with the ET which was estimated on the basis of a water balance method.

\section{Materials and Methods}

The pilot-scale VSSFs were located in the Miyagi prefecture in Japan. The three pilot-scale constructed wetlands were identical in size and construction $(2 \mathrm{~m}$ long $\times 1 \mathrm{~m}$ wide with a $0.55 \mathrm{~m}$ water depth).

The experimental approaches consisted of three runs: Run A contained a poor reed vegetation, Run B contained a dense reed vegetation and Run $\mathrm{C}$ was without reeds (Figure1). The reeds in Run A were two-year old specimens and the reeds in Run B were seven-year old specimens under the condition of high salinity landfill leachate. Inflow, outflow and precipitation were measured in order to evaluate the water budget of the VSSFs. The flow rate was $70 \mathrm{~L}$ per day, and $14 \mathrm{~L}$ of the inflow was intermittently introduced five times a day. The measured parameters were $\mathrm{pH}, \mathrm{COD}, \mathrm{TN}, \mathrm{NH}_{4}-\mathrm{N}, \mathrm{NO}_{2}-\mathrm{N}, \mathrm{NO}_{3}-\mathrm{N}$, TP,air temperature, EC, and Chloride. The air temperature every $30 \mathrm{~min}$ and the amount of dairy precipitation were measured. An investigation of reed vegetation (shoot lengths and shoot numbers) was completed twice a month. A rain gauge was installed at the outflow drain of the VSSF, and the rate of outflow was measured continuously. The ET was estimated based on the water budget method, and the PET was estimated using the Hamon equation. The experimental period of Run A and Run C was from April 2017 to Mach 2018 and that of Run B was from April 2018 to March 2019. Hereafter, these are referred to as 2017 and 2018. 


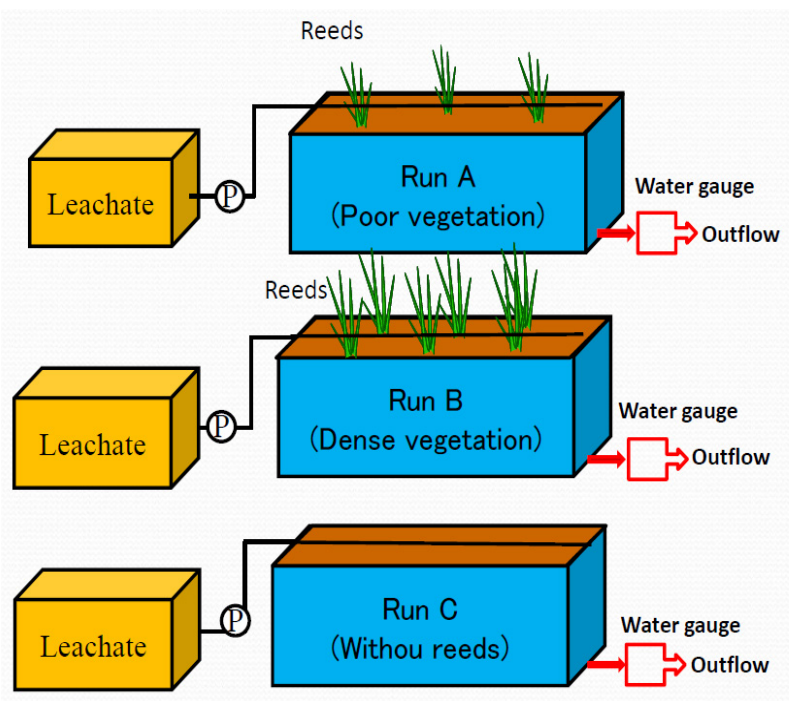

Figure 1. Schematic diagram of VSSFs

\section{Results and Discussions}

\subsection{Salinity of CWs}

Table1 shows the average salinity of inflow and outflow of Run A and Run B during the experimental period.

The average salinities of Run A and Run B inflow were $15.8 \pm 1.9$ and $15.5 \pm 2.8 \mathrm{~g} \cdot \mathrm{Cl} / \mathrm{L}$, and those of Run $\mathrm{A}$ and Run B outflow were $12.0 \pm 2.4$ and $14.8 \pm 2.4 \mathrm{gCl} / \mathrm{L}$, respectively. The salinity of the landfill leachate was very high, and was slightly lower than that of seawater. The salinity of the survival limit of a reed is reported within the range of $12-15 \mathrm{~g} \cdot \mathrm{Cl}^{-} / \mathrm{L}[26,27]$. Therefore, it seemed that it was very difficult for the reed to grow

Table 1. Average salinity of Run A and Run B

\begin{tabular}{cccc}
\hline & unit & Run A & Run B \\
\hline Inflow & $\mathrm{g} \cdot \mathrm{Cl} / \mathrm{L}$ & $15.8 \pm 1.9$ & $15.5 \pm 2.8$ \\
Outflow & $\mathrm{g} \cdot \mathrm{Cl} / \mathrm{L}$ & $12.0 \pm 2.4$ & $14.8 \pm 2.4$ \\
\hline
\end{tabular}

\subsection{Reed Vegetation}

Figures $2 \mathrm{a}$ and $2 \mathrm{~b}$ show the growth change of the shoot length and the number of shoots for Runs A and B during the vegetation period of Run A and Run B. The shoot length was the average reed height from the top of 30 shoots. As shown in Figures $2 \mathrm{a}$ and $2 \mathrm{~b}$, the extension of the reeds of Run A and Run B was increasing until the end of July. The maximum length of Run A reached up to a height of $53.7 \pm 8.1 \mathrm{~cm}$ and that of Run B reached up to $86.7 \pm 13.4 \mathrm{~cm}$.

On the other hand, the number of the shoots per square meter of Run A gradually increased until the middle of August, reaching up to 71 shoots $/ \mathrm{m}^{2}$, and that of Run B increased until the middle of August, reaching up to 798 shoots $/ \mathrm{m}^{2}$. In the reeds of Run A, the growth of shoot length and the increase of the number of shoots were remarkably suppressed and managed to survive under the high salinity condition. On the other hand, in the reeds of Run B, the growth of shoot length was suppressed, but the number of shoots continued to increase over the past 7 years to 789 shoots $/ \mathrm{m}^{2}$ under the high salinity condition.

The shoot length of the Run B reed was 1.5 times that of the Run A reed, and the number of shoots in Run B was more than 10 times that of Run A. In this way, the degree of vegetation greatly differs between the Run A reed and the Run B reed. That is, Run A contained poor vegetation and Run B contained dense vegetation.
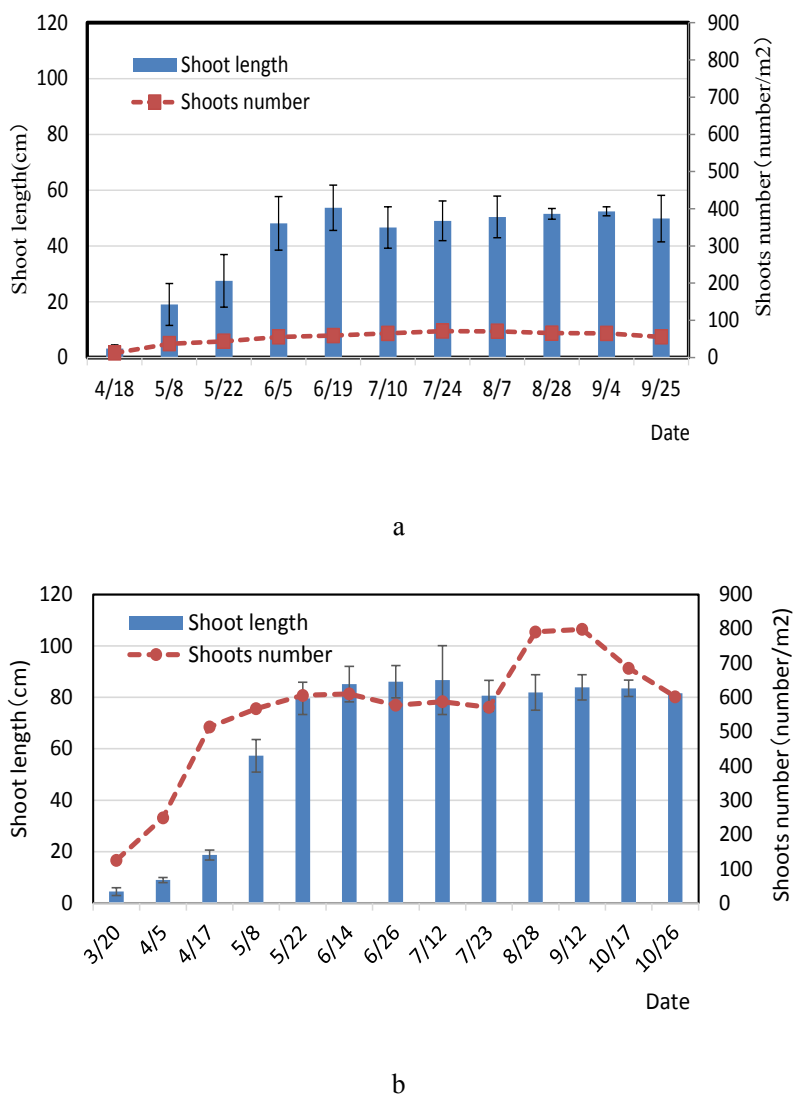

Figure 2. Seasonal growth change of reeds ( a: Run A, b: Run B)

\subsection{Water Budget of CWs}

The evapotranspiration of plants has a close relation to the water budget in the CWs and influenced the purification process [28].

Unlike natural systems, water behavior in $\mathrm{CW}$ is partly controlled by human interests. In the present experiment, the input streams from the system do not exit, since all treatment beds were sealed. Therefore, the parameters of the water budget are inflow, precipitation, evaporation, transpiration and outflow. The water budget of the $\mathrm{CW}$ is expressed as follows [29, 30] 


$$
\mathrm{ET}=\mathrm{Q}_{\text {in }}+\mathrm{P}-\mathrm{Q}_{\text {out }}
$$

ET: Evapotranspiraion $(\mathrm{mm} / \mathrm{d})$

P: Daily Precipitation $(\mathrm{mm} / \mathrm{d})$

$\mathrm{Q}_{\text {in }}$ : Inflow $(\mathrm{mm} / \mathrm{d})$

Qout: Outflow (mm/d)

\section{$\mathrm{ET}=$ Evaporation + Transpiration \\ Total inflow $=$ Inflow + Precipitation}

Figure 3 shows the variation in the daily water balance (total inflow, outflow and ET) of each run during the period of April 2017 to Mach 2018 and that of April 2018 to March 2019. Figure 3-a, 3-b and 3-c are Run A, Run B, and Run $\mathrm{C}$, respectively. In Figure 3-a, ET gradually increased in April, remained around $5-7 \mathrm{~mm} / \mathrm{d}$ from June to December, and then decreased to $2 \mathrm{~mm} / \mathrm{d}$. ET in Run A was slightly affected by air temperature. The increase of ET might be due to the growth of reeds. The average of ET in Run A was $4.2 \pm 2.7 \mathrm{~mm} / \mathrm{d}$. The maximum rate of ET was $11.3 \mathrm{~mm} / \mathrm{d}$ and the minimum rate was $-7.3 \mathrm{~mm} / \mathrm{d}$. In figure 3-b, ET in Run B remained in the range of
$6-8.5 \mathrm{~mm} / \mathrm{d}$ throughout the experiment, and was almost constant. That is, the ET in Run B did not appear to be affected by air temperature at all. The average rate of ET in Run B was $7.4 \pm 2.5 \mathrm{~mm} / \mathrm{d}$. The maximum rate of ET was $20.8 \mathrm{~mm} / \mathrm{d}$ and the minimum was $0.5 \mathrm{~mm} / \mathrm{d}$. In Figure 3-c, the ET rate in Run $\mathrm{C}$ remained in the range of $3-4.5 \mathrm{~mm} / \mathrm{d}$ from April to December, and then decreased to $1 \mathrm{~mm} / \mathrm{d}$. ET in Run C was slightly affected by air temperature, as in Run A. The average rate of ET in Run $\mathrm{C}$ was $3.0 \pm 2.4 \mathrm{~mm} / \mathrm{d}$. The maximum rate of ET was $10.0 \mathrm{~mm} / \mathrm{d}$ and the minimum was $-11.8 \mathrm{~mm} / \mathrm{d}$. Therefore, the highest ET was in the dense vegetation Run B, followed by the poor vegetation Run A, and the lowest was Run C without reeds. In our study, the ETs in the poor vegetation bed and dense vegetation bed were higher than that in the willow bed in Poland which was demonstrated by Agopsowicz [31]. The difference may be due to climatic conditions such as temperature in the two countries.

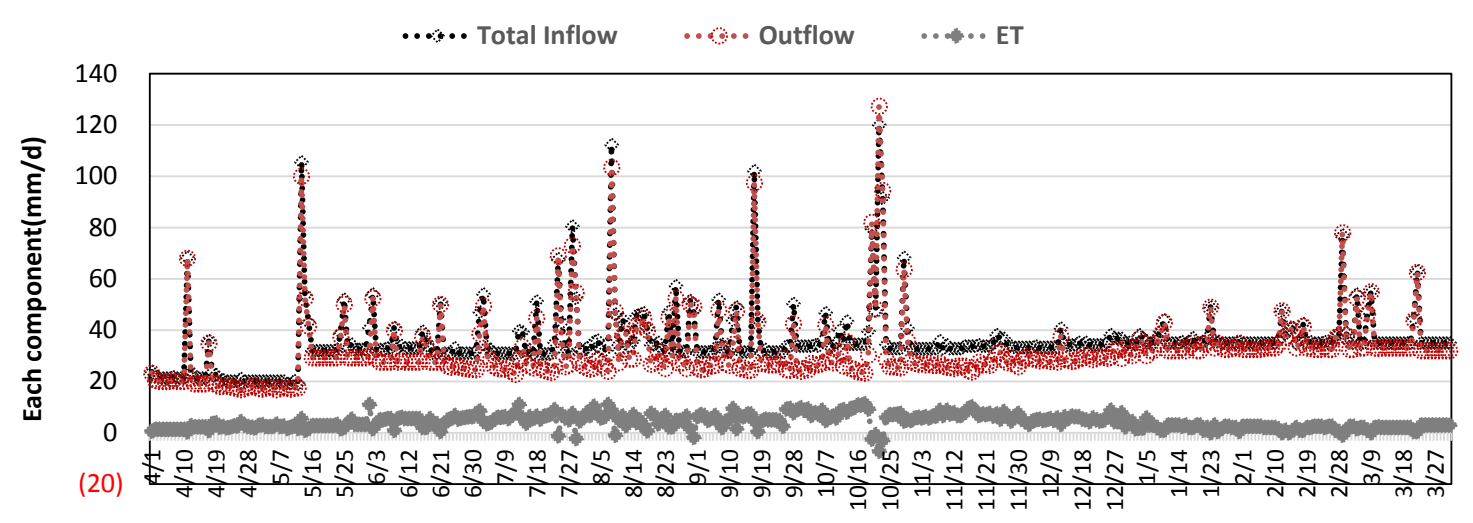

Date

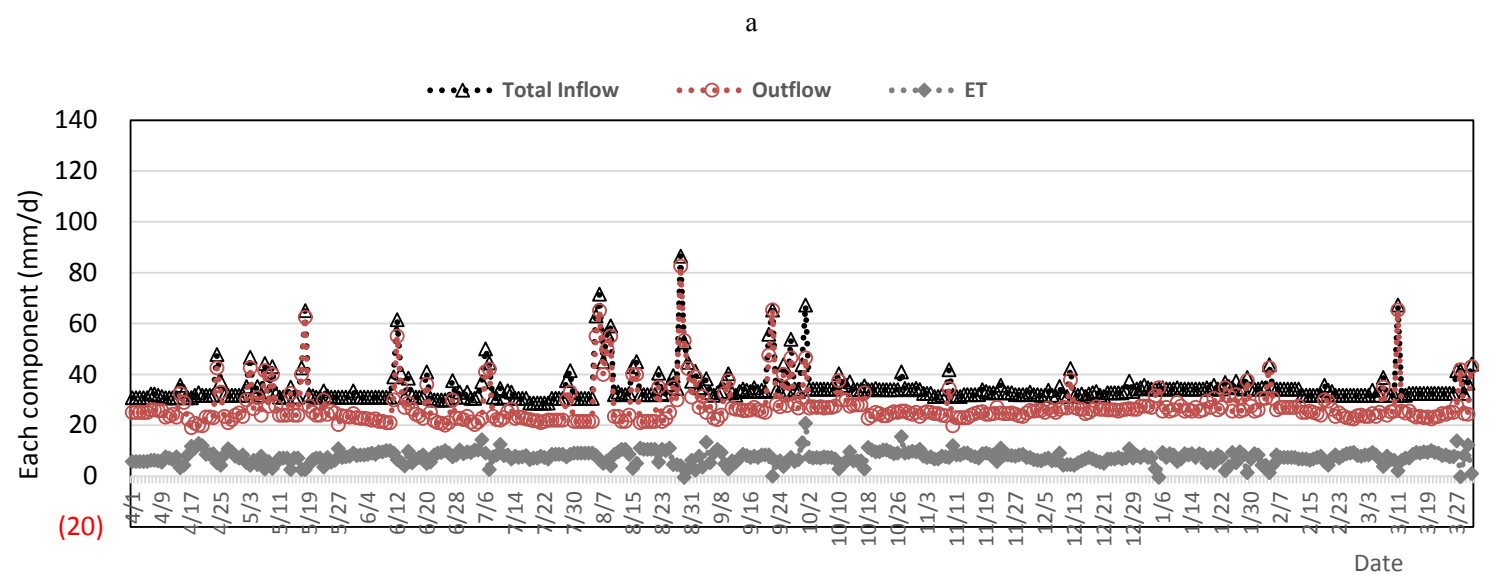




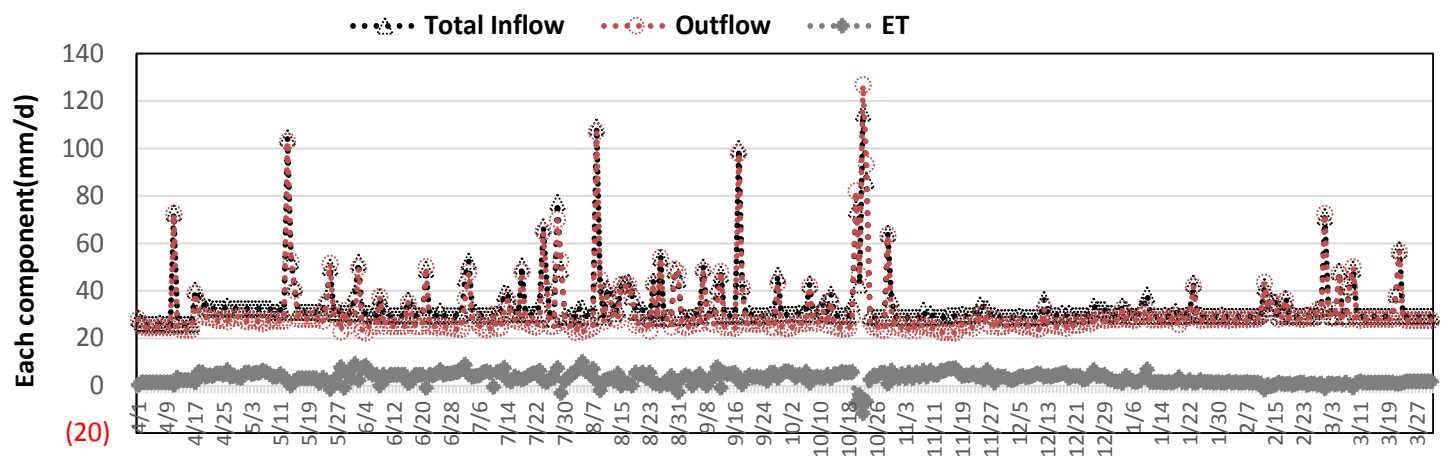

Date

Figure 3. Variation of water balance (a: Run A, b: Run B, c: Run C)

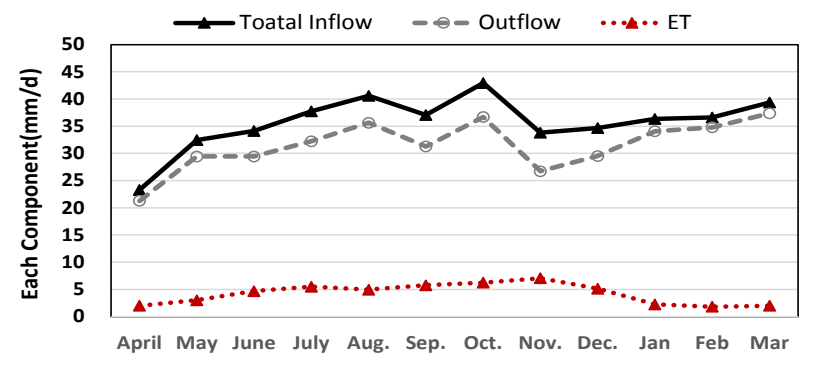

Month

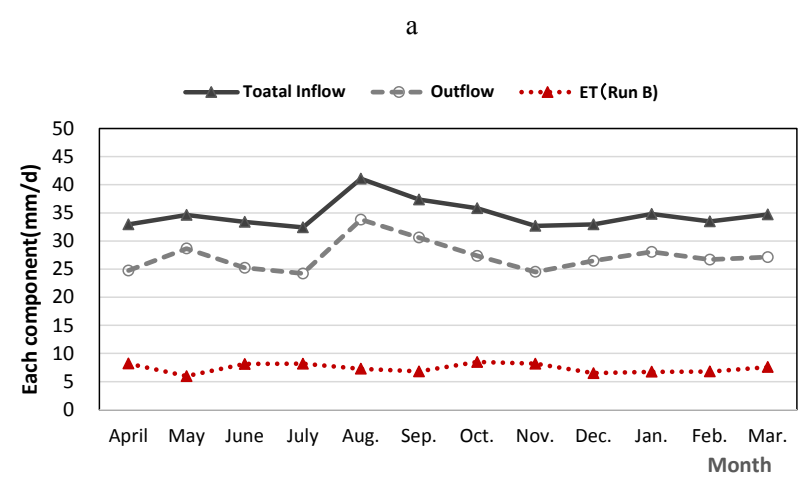

b

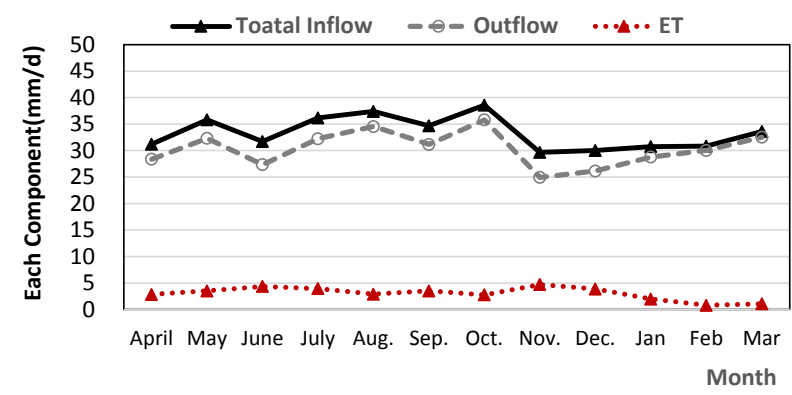

c

Figure 4. Variation of monthly mean water balance (a: Run A, b: Run B, c: Run C)
Figure 4 shows the monthly mean water balance of the three runs. The ET was estimated on the basis of the water budget method. Figure 4-a, 4-b, 4-c are the water balance of Run A, that of Run B, and that of Run C, respectively. In Figure 4-a, the ET rate of Run A gradually increased from April to November, and reached a peak with an ET rate of $7 \mathrm{~mm} / \mathrm{d}$ in November. In figure $4-b$, that of Run B remained $6-8.5 \mathrm{~mm}$ throughout the year. In Figure 4-c, the ET rate in Run C remained in the range of $3-4.5 \mathrm{~mm} / \mathrm{d}$ from April to December, and then decreased to $1 \mathrm{~mm} / \mathrm{d}$.

\subsection{Monthly Ratio of ET to Total Inflow}

Figure 5 shows the ratio of ET to total inflow of the three runs.

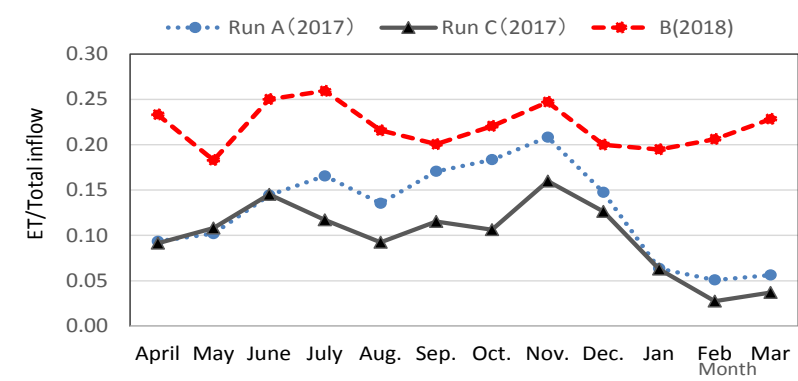

Figure 5. Monthly ratio of ET to total inflow of three runs

Run A was within the range of 0.05 to 0.21 , and with an average of 0.13 . Run $\mathrm{C}$ was within the range of 0.03 to 0.16 , and with an average of 0.10 . Although the ratio of Run A was higher than that of Run C from July to November, the trend of the monthly variation of Run A and Run $\mathrm{C}$ was very similar. That is, the monthly change of the evapotranspirated volumes in the poor vegetation bed was similar to that of the bed without reeds. On the other hand, Run B was within the range of 0.19 to 0.26 , and with an average of 0.22 , and fairly constant throughout the year with no seasonal variation. Thus, there was large difference in the ET variation between 
dense vegetation and poor vegetation. Silva, et al. demonstrated that the ratio of evapotranspirated volumes were 0.38 in plant beds and 0.16 in beds without plants in sub-humid tropical climates in Brazil where temperatures remained at an average $16^{\circ} \mathrm{C}$ to $30^{\circ} \mathrm{C}$ [32]. Sendai is in the temperate zone where temperatures remained at an average $1.5{ }^{\circ} \mathrm{C}$ to $24{ }^{\circ} \mathrm{C}$. Therefore, the ratio of evapotranspirated volumes varied greatly with climatic condition such as subtropical and temperate zones.

\subsection{Comparison of ET and PET}

The PET was estimated on the basis of Hamon equation. Hamon equation was expressed as follow [33]:

$$
\mathrm{PET}=0.14 \mathrm{D}_{0}^{2} \mathrm{P}_{\mathrm{i}}
$$

PET: Potential evapotranspiration $(\mathrm{mm} / \mathrm{d})$,

$\mathrm{D}_{0}$ : Day time length $(\mathrm{x} / 12 \mathrm{hrs})$,

$\mathrm{P}_{\mathrm{i}}$ : Saturated absolute humidity $\left(\mathrm{mg} / \mathrm{m}^{3}\right)$

Figure 6 shows the variation of the monthly average air temperature and the monthly average of PET. Figure 6-a is the change in 2017 and Figure 6-b is that in 2018. In both figures, the PET began higher with rising air temperatures from spring to summer, reaching a peak in July and began lower with descent of the air temperature from autumn to winter. The PET was influenced strongly by air temperature. The variations of PET in 2017 and 2018 showed the same shape.

Figure 7 shows the comparison of the monthly average of PET and the monthly average of ET of three runs. Figure 7-a shows the variation of the ET of Run A and Run B in 2017, and Figure 7-b is that of Run B in 2018. In figure 7-a, the changes in the PET and the ET of Run A and Run $\mathrm{C}$ were similar from April to July, but after August, they behaved differently. In figure 7-b, the changes in the PET and the ET of Run B were quite different. Thus, the changes in the ET in VSSFs differed according to the vegetation difference of reeds, and also in PET.

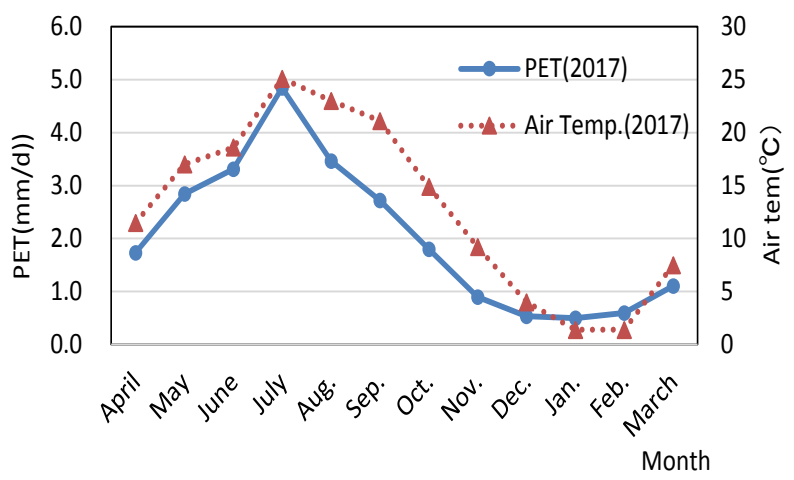

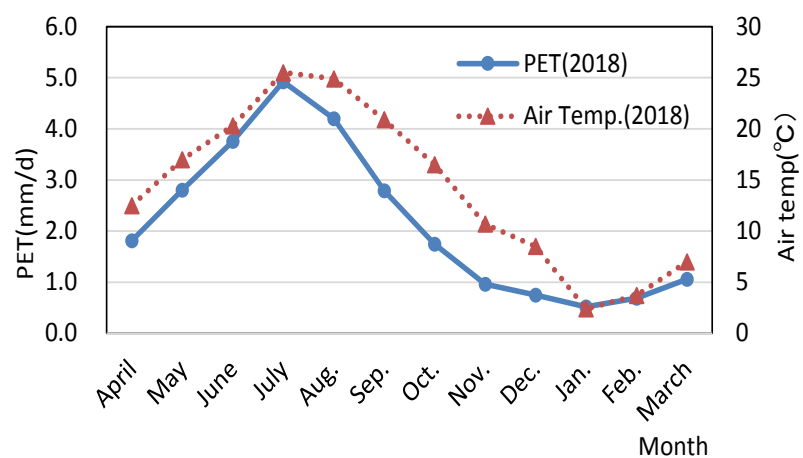

b

Figure 6. Average of monthly variations of PET and air temperature (a: 2017, b: 2018)

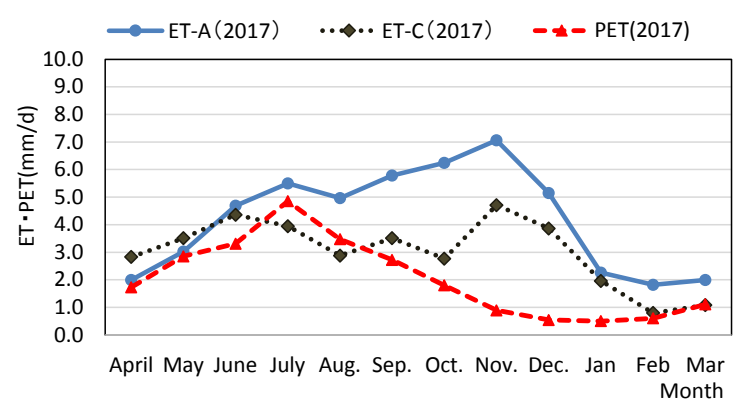

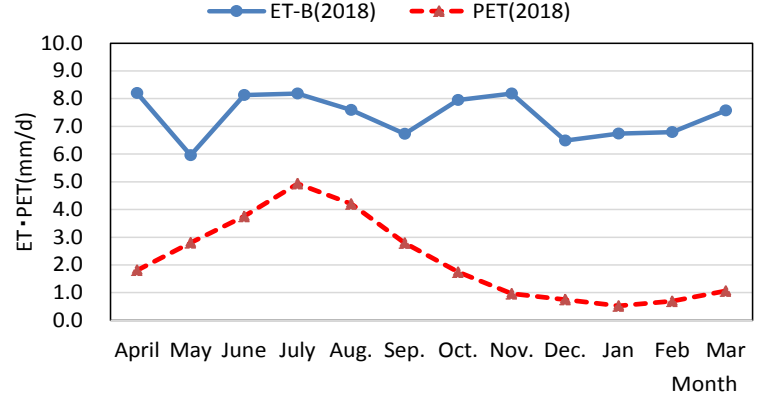

Figure 7. Comparison of average of monthly variations of ET and PET (a: 2017, b: 2018) 
Figure 8 shows the annual ET rate and the annual PET rate in 2017 and 2018. The ET rates of Run A, Run B and Run C were $1535 \mathrm{~mm}, 2702 \mathrm{~mm}$ and $1101 \mathrm{~mm}$, respectively. On the other hand, the annual PET rates in 2017 and 2018 were $741 \mathrm{~mm}$ and $791 \mathrm{~mm}$, respectively. The ET rate of the dense reed vegetation was higher than that of a poor reed vegetation and a lack of reeds. There was a difference in the ET rate due to the difference in reed vegetation in VSSF. Furthermore, the ET rate is much different from the PET rate. When assessing ET of CWs, it is necessary to consider the vegetation.

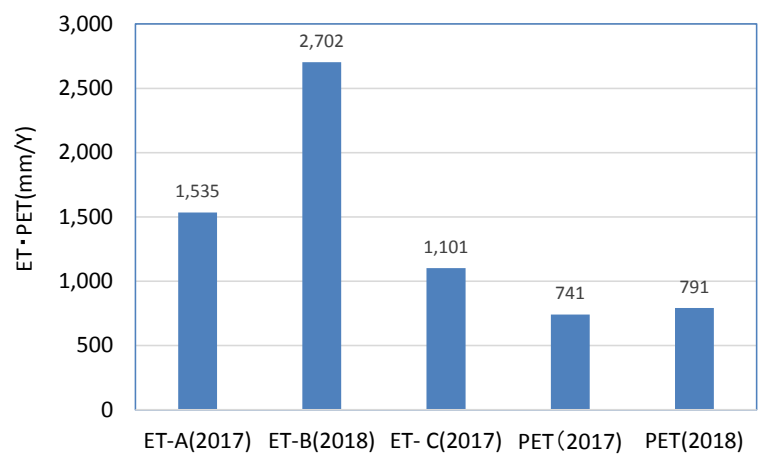

Figure 8. Annual ET rate and PET rate of 2017and 2018

The annual precipitation rates in 2017 and in 2018 were $1420 \mathrm{~mm}$ and $1077 \mathrm{~mm}$. The annual ET rate in Run A was 1.08 times higher than the precipitation rate in 2017. That in Run B was 2.51 times higher than the precipitation rate in 2018. That in Run $\mathrm{C}$ was 0.78 times lower than the precipitation rate in 2017. Agopsowicz demonstrated that ET of three-month-old willow sprouts was 1.6-1.8 times higher than the average precipitation rate in Poland [31]

\subsection{Treatment Performance}

In the VSSF of Run B, where water loss was typically high, the calculation of pollutant removal efficiency using results of concentration might lead to significant errors. Therefore, it was necessary to evaluate the load reduction rate obtained from the water budget.

Removal efficiencies of pollutants in VSSF were calculated, based on concentrations (eq.(3)) and load reduction rates were calculated based on loads (eq.(4)).

$$
\text { Removal efficiency (RE) }=\frac{C_{\text {in }}-C_{\text {out }}}{C_{\text {in }}} \times 100 \%
$$

Where $C_{\text {in }}$ and $C_{\text {out }}$ are the mean concentrations $(\mathrm{mg} / \mathrm{L})$ of a pollutant in the inflow and the outflow, respectively.

$$
\text { Load reduction rate }(\mathrm{LRR})=
$$

$$
=\frac{\left(C_{\text {in }} \times Q_{\text {in }}\right)-\left(C_{\text {out }} \times Q_{\text {out }}\right)}{C_{\text {in }} \times Q_{\text {in }}} \times 100 \%
$$

Where $Q_{\text {in }}$ and $Q_{\text {out }}$ are the amount of inflow and outflow, and $C_{i n} \times Q_{\text {in }}=M_{\text {in }}(\mathrm{mg})$ and $C_{\text {out }} \times Q_{\text {out }}=M_{\text {out }}$ are inflow and outflow mass load, respectively.

Table 2, 3 and 4 show the removal efficiencies and the load reduction rates of $\mathrm{COD}, \mathrm{NH}_{4}-\mathrm{N}$ and $\mathrm{TN}$ of three runs. In Table 2, the REs of COD of Run A, Run B and Run C were $43.7 \pm 18.7,46.6 \pm 12.6,37.4 \pm 18.8 \%$, respectively. The highest RE was Run B, followed by Run A, and the lowest RE was Run C. However, the difference in RE between Run A and Run B was very small. The LRRs of the COD of Run A, Run B and Run C were $44.9 \pm 15.6$, $54.9 \pm 10.5,36.0 \pm 17.4 \%$, respectively. The order of the LRR was the same as that of the RE. However, the difference in LRR among the three runs was larger than that in RE. Compared to the RE and LRR of COD, both were almost the same in Run A and Run C. On the other hand, LRR was $8.8 \%$ higher than RE. Thus, large water loss due to dense vegetation ET provided a great influence on the treatment performance.

In Table 3, the REs of the $\mathrm{NH}_{4}-\mathrm{N}$ of Run A, Run B and Run $\mathrm{C}$ were $40.3 \pm 22.8,40.2 \pm 15.5,33.8 \pm 9.48 \%$, respectively. There were no differences in the removal efficiency between Run A and Run B. The LRRs of the $\mathrm{NH}_{4}-\mathrm{N}$ of the three runs were $41.5 \pm 10.8,49.1 \pm 12.4$, $31.6 \pm 9.4 \%$, respectively. The highest LRR was Run B, followed by Run A, and the lowest LRR was Run C. Although there were no differences between the RE and LRR in Run A and Run C, there was large difference between the RE and LRR in Run B. Compared to the RE and LRR of $\mathrm{NH}_{4}-\mathrm{N}$, both are almost the same in Run A and Run C. On the other hand, LRR was $8.9 \%$ higher than RE.

In Table 4, the REs of the TN of Run A, Run B and Run $\mathrm{C}$ were $30.0 \pm 22.8,27.5 \pm 28.5,29.5 \pm 21.78 \%$, respectively. There were no differences in the removal efficiency among the three runs.

The LRRs of TN of the three runs were $31.4 \pm 20.7$, $38.3 \pm 19.5,26.2 \pm 21.6 \%$, respectively. The highest LRR was Run B, followed by Run A, and the lowest LRR was Run C. However, there were no differences between the RE and LRR in Run A and Run C. On the other hand, Run $B$ had a large difference between the RE and LRR.

Similar to COD and $\mathrm{NH}_{4}-\mathrm{N}$, the LRR in TN was higher than the RE.

The reed vegetation did not affect the RE estimated from the pollutants concentration in the VSSFs, but provided a large impact on the LRR estimated from the water budget. 
Table 2. Treatment performance of COD

\begin{tabular}{ccccc}
\hline & unit & Run A & Run B & Run C \\
\hline Inflow & $\mathrm{mg} / \mathrm{L}$ & $242.3 \pm 34.5$ & $255.1 \pm 25.4$ & $237.6 \pm 36.2$ \\
Outflow & $\mathrm{mg} / \mathrm{L}$ & $133.9 \pm 43.1$ & $136.2 \pm 24.4$ & $146.2 \pm 43.3$ \\
Removal efficiency & $\%$ & $43.7 \pm 18.7$ & $46.6 \pm 12.6$ & $37.4 \pm 18.8$ \\
\hline Inflow load & $\mathrm{g} / \mathrm{d}$ & $15.3 \pm 2.4$ & $16.4 \pm 2.0$ & $13.9 \pm 2.2$ \\
Outflow load & $\mathrm{g} / \mathrm{d}$ & $8.4 \pm 3.0$ & $7.4 \pm 2.4$ & $8.7 \pm 2.2$ \\
Load reduction rate & $\%$ & $44.9 \pm 15.6$ & $54.9 \pm 10.5$ & $36.0 \pm 17.4$ \\
\hline
\end{tabular}

Table 3. Treatment performance of $\mathrm{NH}_{4}-\mathrm{N}$

\begin{tabular}{ccccc}
\hline & unit & Run A & Run B & Run C \\
\hline Inflow & $\mathrm{mg} / \mathrm{L}$ & $318.9 \pm 48.8$ & $327.8 \pm 30.7$ & $299.6 \pm 42.8$ \\
Outflow & $\mathrm{mg} / \mathrm{L}$ & $186.9 \pm 75.1$ & $196.2 \pm 41.7$ & $196.0 \pm 30.5$ \\
Removal efficiency & $\%$ & $40.3 \pm 22.8$ & $40.2 \pm 15.5$ & $33.8 \pm 12.3$ \\
\hline Inflow load & $\mathrm{g} / \mathrm{d}$ & $20.2 \pm 4.0$ & $21.0 \pm 1.8$ & $17.5 \pm 2.5$ \\
Outflow load & $\mathrm{g} / \mathrm{d}$ & $11.7 \pm 5.3$ & $10.7 \pm 2.3$ & $11.8 \pm 1.3$ \\
Load reduction rate & $\%$ & $41.5 \pm 10.8$ & $49.1 \pm 12.4$ & $31.6 \pm 9.4$ \\
\hline
\end{tabular}

Table 4. Treatment performance of $\mathrm{TN}$

\begin{tabular}{ccccc}
\hline & unit & Run A & Run B & Run C \\
\hline Inflow & $\mathrm{mg} / \mathrm{L}$ & $333.1 \pm 47.5$ & $345.5 \pm 29.9$ & $330.1 \pm 48.8$ \\
Outflow & $\mathrm{mg} / \mathrm{L}$ & $229.5 \pm 77.9$ & $250.5 \pm 33.5$ & $232.8 \pm 70.0$ \\
Removal efficiency & $\%$ & $30.0 \pm 22.8$ & $27.5 \pm 28.5$ & $29.5 \pm 21.5$ \\
\hline Inflow load & $\mathrm{g} / \mathrm{d}$ & $21.1 \pm 4.1$ & $22.2 \pm 3.1$ & $19.3 \pm 2.9$ \\
Outflow load & $\mathrm{g} / \mathrm{d}$ & $14.4 \pm 5.5$ & $13.7 \pm 3.5$ & $13.9 \pm 3.9$ \\
Load reduction rate & $\%$ & $31.4 \pm 20.7$ & $38.3 \pm 19.5$ & $26.2 \pm 21.6$ \\
\hline
\end{tabular}

\section{Conclusions}

We examined the effect of the reed vegetation on the ET and treatment performance using VSSFs, and obtained the following conclusions. The difference in the reed vegetation provided a large difference in the ET rate in VSSFs. That is, the ET in the dense vegetation bed was higher than that of the poor vegetation bed. The high ET in the VSSFs reduced the outflow load and affected the removal efficiency. The annual variation of ET and PET was very different, and the seasonal variation was small.

Even in the water balance of VSSFs, it was necessary to estimate the ET in consideration with the reed vegetation.

Although the removal rates calculated from the concentration between inflow and outflow did not differ between the dense vegetation bed and the poor vegetation bed, the load reduction rates calculated from the water budget differed between the dense vegetation and the poor vegetation.

\section{REFERENCES}

[1] Lee C.-G., Fletcher T. D., Sun G., "Nitrogen removal in constructed wetland systems," Engineering. Life Scence., Vol.9, No.6, pp.11-22, 2009. DOI: 10.1002/elsc.200800049.

[2] Vymazal J., "Constructed wetlands for waste water treatment," Water, Vol.2, pp. 530-549, 2010. DOI: $10.3390 /$ w2030530.

[3] Vymazal J., "The use of constructed wetlands with horizontal sub-surface flow for various types of wastewater." In Proceedings of the 11th International Conference on Wetland Systems for Water Pollution Control, Indol, India, pp. 1-15, 2008.

[4] Bulc T.G., "Long-term performance of a constructed wetlands for landfill leachate treatment," Ecological Engineering, Vol. 26, pp. 365-374, 2006. DOI: 10.1016/j.ecoloeng.2006.01.003.

[5] Arosson P., and Perttu K., "Willow vegetation filters for wastewater treatment and soil remediation combined with biomass production," The Forestry Chronicle, Vol. 77. No.2, pp. 293-299, 2001.

[6] Perttu K., and Kowalik P., Salix vegetation filters for purification of waters and soils, Biomass and Bioenergy, Vol. 12. No.1, pp. 9-19, 1997. https://:doi.org/10.1016/S0961-95 34(96)00063-3

[7] Brix H., "Do macrophytes play a role in constructed wetlands?," Water Science and Tecnology, Vol.35. No.5, pp. 11-17, 1997.

[8] Tanner C. C., and Kadlec R. H., "Oxygen flux implications of observed nitrogen removal rates in subsurface-flow treatment wetlands," Water Science and Technology, Vol.48. No.5, pp. 191-198, 2003.

[9] Gangnon V., Chzarenc F., Comeau Y. and Brisson J., "Influence of macrophyte species on_microbial density and activity in constructed wetlands," Water Scence and 
Technology, Vol.56. No.3, pp. 248-254, 2007. DOI: 10.2166/wst.2007.510.

[10] Vymazal J. and Kropfelva L., "Horizontal flow constructed wetlands" in Watstwater treatment in constructed wetlands with horizontal sub-surface flow, Environmental Pollution 14, Springer, London, 2014, pp.234-262.

[11] Shelef O., Gross A., and Rachmilevitch S., "Role of plants in a constructed wetland: Current and New perspectives," Water, Vol. 5, pp. 405-419, 2013. DOI: 10.3390/w5020405.

[12] Brandon Lott, R., and Hunt, R. J., "Estimating evapotranspiration in natural and constructed wetlands," Wetland, Vol. 21. No.4, 614-628, 2001.

[13] Chazarenc F., Naylor S., Comeau Y., Merlin G., and Brisson J., "Modelling the effect of plants and peat on evapotranspiration in constructed wetlands," International Journal of Chemical Engineering, Vol. 2010, pp. 1-6, 2010. DOI: $10.1155 / 2910 / 412734$.

[14] Dobson M. C.,and Moffat A. J., "A re-evaluation of objections to tree planting on containment landfills, " Waste Management and Research, Vol.13. No.5, pp.579-600, 1995. https://doi.org/10.1016/S0734242X (05)80036- 9.

[15] Bialowiec A., Wojnowska-Baryla I., and Agopsocz M., "Evapo-transpiration in Ecological Engineering," Evapotranspiration, pp.395-418, 2011. https://www.researc hgate.net/pulication/221911185

[16] Bialowiec A., Wojnowska-Baryla,I., Hasso-Agopsowicz M., "The controlling of landfill leachate evapotranspiration from soil-plant systems with willow: Silix amygralina L.," Waste Management and Research, Vol.25, No.1, pp. 61-67, 2007. DOI: $10.1177 / 0734242 X 07073106$.

[17] Persson G.,and Lindroth A., "Stimulating evaporation from short rotation forest variation within and between seasons," Journal of Hydrology, Vol. 156, pp. 271-293, 1994.

[18] Elowson S., "Willow as a vegetation filter for cleaning of polluted drainage water from agricultural land," Biomass and Biomass, Vol. 16, No. 4, pp. 281-290, 1999. https://doi.org/10.1016/S0961-9534(98)00087-7.

[19] Dulohery C. J., Kolka R. K., and Mckevlin M. R., "Effects of willow overstory on planted seedings in bottomland restoration," Ecological Engineering, Vol. 15, pp.57-66, 2000 .

[20] Hasselgren K., "Use of municipal waste products in energy forestry: highlights from 15 years of experience," Biomass and Bioenergy, Vol.15, No.1, pp. 71-74, 1998. DOI: 10.1016/S0961-9534(97)100512-6.

[21] Cossu R., Haarstad K.,Lavagnolo M. C.,and Littarru, P., "Removal of municipal solid waste COD and NH4-N by phyto-reduction: a laboratory-scale comparison of terrestorial and aquatic species at different organic loads," Ecological Engineering, Vol. 21, pp. 164-173, 2001.

[22] Yano T., Okanuma M., Kumagai Y., Sato K., Inoue-Kohama A. and Enari K., "Effect of salinity on in the treatment of high salinity landfill-leachate using HSF," Journal of Environmental Science and Engineering, Vol. 3, No.3, pp. 142-150, 2014.

[23] Yano T., Yamada K., Nakayama M., Inoue-kohama A., Sato S., and Enari K., " Evapotranspiration and removal performance in the treatment of high salinity landfill-leachate using HSF," Journal of Environmental Science and Engineering, Vol.5, No.9, pp. 440-450, 2016. DOI: $10.17265 / 2162-5263 / 2016.09 .006$

[24] Yano T., Yamada K., Nakayama M., Inoue-kohama A., Sato S., and Enari K., "Influence of growth of reeds on evapotranspiration in horizontal subsurface flow constructed wetlands," Environment and Ecology Research, Vol.5, No.6, pp.427-435, 2017. DOI:10.13189/eer.2017.05 0603.

[25] Matoh T., Matsushita N. and Takahashi E., "Salt tolerance of the reed plant Phagrgmites communis," Physiologia Plantarum, Vol.72, pp. 8-14, 1988.

[26] Barr M. J. and Robinson H. D., "Constructed wetlands for landfill leachate treatment," Waste Management and Research, Vol.17, pp.498-504, 1999.

[27] Mauchamp A. and Mesleard F., "Salt tolerance Phargamites australis populations from coastal Mediterranean marshes," Aquatic Botany, Vol.70, pp.39-52, 2001

[28] Rozkosny M., Salec J. and Salec J., "Water balance of the constructed wetlands - A study of the macrophytes evapotranspiration," Proceeding of $10^{\text {th }}$ International Conference on Wetland Systems for Pollution Control, Lisbon, Portugal, pp.123-129. 2006.

[29] Eckhardt D. A. V., Sueface J.M and Peverly J., "A constructe wetland system for treatment of landfill leachate, Monroe Country, New York," in Mulamoottil G., McBean E.A., Rovers, F., edit., Constructed Wetlands for the Landfill Leachate, Leis Publishers, London, 2009, pp. 205-222.

[30] Kadlec R. M., Knight R. L., Vymazal J., Brix H., Cooper R., and Harberl R., "Framework for interpreting and predicting water quality improvement" in Constructed wetlands for pollution control, processes, performance, design and operation, Scientific and Technical Report No.8, IWA Publishing London, UK, 2010, pp.41-54.

[31] Bialowiec A., Albuquerque A., Randerson P. F., "The influence of evapotranspiration on vertical flow subsurface constructed wetland performance," Ecological Engineering, Vol.7, pp. 89-94, 2014. http://dx.doi.org/10.1016/j.ecoleng. 2014.03.032.

[32] Silva É. D., Araújo Almeidia R.,Rodrigues Siqueria E., and Silva Á. R., Water budget constructed wetland system with subsurface vertical flow in sub-tropical climate, Modern Environmental Science and Engineering, Vol.1, No.5, pp.235-242, 2015. DOI:10.15341/mese(2333-2581)/05.01.2 $015 / 004$.

[33] Japan Society of Civil Engineers, Hydraulic Formula handbook, chapter 2, 1985, pp.144-145(in Japanese) 